\title{
Pierre Robin Sequence : Incidence of Speech-Correcting Surgeries and Fistula Formation
}

\section{Gustafsson, Charlotta}

2020-03

Gustafsson, C , Vuola , P , Leikola , J \& Heliövaara , A 2020 , ' Pierre Robin Sequence :

Incidence of Speech-Correcting Surgeries and Fistula Formation ', Cleft Palate -

Craniofacial Journal , vol. 57 , no. 3 , pp. 344-351 . https://doi.org/10.1177/1055665619874991

http://hdl.handle.net/10138/327049

https://doi.org/10.1177/1055665619874991

acceptedVersion

Downloaded from Helda, University of Helsinki institutional repository.

This is an electronic reprint of the original article.

This reprint may differ from the original in pagination and typographic detail.

Please cite the original version. 


\section{Pierre Robin Sequence: Incidence of Speech-Correcting Surgeries and}

\section{Fistula Formation}

Charlotta Gustafsson, MD, Pia Vuola, MD, Junnu Leikola, MD, DDS, PhD and Arja

Heliövaara, DDS, PhD

Cleft Palate and Craniofacial Center, Department of Plastic Surgery, Helsinki University Hospital, Helsinki, Finland

Correspondence to

Charlotta Gustafsson, Cleft Palate and Craniofacial Center, Department of Plastic Surgery, Helsinki University Hospital, P.O. Box 266, FI-00029 HUS, Finland. E-mail:

charlotta.gustafsson@helsinki.fi 


\section{ABSTRACT}

Objective: Children with Pierre Robin sequence (PRS) and cleft palate have a high rate of velopharyngeal insufficiency (VPI) following primary palatoplasty. Our purpose was to determine the long-term incidence of speech-correcting surgeries (SCSs) and fistula rates in PRS after primary palatoplasty and the influence of possible causal factors.

Design: A retrospective single-center, observational chart review study.

Participants: After exclusion, the study cohort comprised 78 non-syndromic PRS children (48 females) born between 1990 and 2009 and treated at the Cleft Palate and Craniofacial Center of Helsinki University Hospital, Finland. Causal factors included gender, surgeon, age at primary palatoplasty, surgical technique, airway obstruction in infancy, and cleft severity. We analyzed the outcome at age 8 years and at data retrieval, with a median follow-up of 14 years (range 8-27 years).

Results: Thirty-four children (43.6\%) received SCS by age 8 years, and of the 19 postoperative fistulas (24.4\%), 6 (7.7\%) underwent closure. At data retrieval, 37 children (47.4\%) had undergone SCS and $8(10.3 \%)$ had a fistula closure. Median age at SCS was 6 years. The results showed no significant association for gender, surgeon, age at primary palatoplasty, surgical technique, cleft severity, or airway obstruction in infancy regarding incidence of SCS, fistulas, or repaired fistulas.

Conclusion: PRS in children is associated with a high incidence of SCS and fistula formation, which necessitates accurate clinical follow-up and observation of speech development. The development of VPI in PRS is complex and most likely involving multiple factors. 


\section{INTRODUCTION}

Pierre Robin sequence (PRS) (Robin et al., 1923), a rare condition affecting 1 in 8000 to 1 in 14000 infants (Bush and Williams, 1983; Printzlau and Andersen, 2004; Vatlach et al., 2014), includes micrognathia, a retroposed tongue (glossoptosis), and airway obstruction (Breugem et al., 2016). It is often associated with a wide U-shaped cleft palate (Logjes et al., 2018). Such infants suffer from breathing problems, ranging from mild to severe obstruction, and feeding difficulties, resulting in failure to thrive (Benjamin and Walker, 1991). Within the first few months, however, the majority outgrow these problems. This sequence often occurs concomitantly with other syndromes (syndromic PRS) and anomalies, but also in isolation (non-syndromic PRS) (Basart et al., 2015).

Hypernasal speech and articulation errors may develop after primary palatoplasty, also known as velopharyngeal insufficiency (VPI) (Glade and Deal, 2016). The developmental mechanisms of VPI are not fully understood, but its impact on a child's psychological health and social relationships is often detrimental. When the VPI is severe enough and conservative management fails to improve the associated articulation issues, speech-correcting surgery (SCS) is essential (Becker et al., 2004). A possible complication after palatoplasty is oronasal fistulas, which require subsequent closure and have an adverse impact on speech outcome.

Studies often focus on the treatment of PRS infants' airway obstruction, with only a few examining the outcome of speech development. Results for SCS rates and fistula formation are inconsistent, and study settings are heterogeneous, comparing speech between PRS and cleft palate only (ICP) (Goudy et al., 2011; Stransky et al., 2013; Hardwicke et al., 2016) and non-syndromic (nsPRS) with syndromic PRS (s-PRS) (Witt et al., 1997; de Buys Roessingh et al., 2008; Patel et al., 2012). Findings are often difficult to compare because between centers the diagnostic criteria for PRS and thresholds for SCS differ. Little is known about the effect of initial PRS cleft severity on longterm outcome. 
This observational study analyzed long-term results in ns-PRS regarding SCS, postoperative fistulas, and frequency of operated fistulas. We also compared the influence of possible causal factors. Based on our clinical experience, we believe this population has a high tendency for severe VPI and the subsequent need for SCS.

\section{METHODS}

\section{Patients and study design}

In this retrospective, single-center, observational study, we examined the postoperative outcome after primary palatoplasty in children with PRS who were followed up over an 8- to 27-year period. Our study group comprised PRS children born between 1990 and 2009 who had undergone one-stage primary palatoplasty at the Cleft Palate and Craniofacial Center of Helsinki University Hospital, Finland. Data originated from medical charts in the hospital's archive and database, and Helsinki University Hospital approved the study protocol. Each PRS diagnosis was set by the cleft team, but occasionally by genetic consultation to identify syndromic children. The PRS diagnosis comprised micrognathia, U-shaped cleft, and respiratory obstruction in infancy, and glossoptosis, if mentioned in the records. We excluded patients with palatoplasty techniques performed in a two-stage procedure, associated syndromes or anomalies in the craniofacial region, and cognitive disabilities. Patients with syndromes diagnosed later during the follow-up were also excluded.

\section{Speech assessment}

The speech assessment followed standard protocols of the cleft team and was performed at 3, 5-6, 8, and 10 years up to the age of 16 years or longer, if needed. VPI severity, rated on a 5-point scale as previously described (Gustafsson et al., 2018), was based on nasal air emission, hypernasality, and difficulty with pressure consonants /p, t, k/. The assessment was performed with both perceptual and instrumental (nasometer and videofluorography and sometimes even nasopharyngoscopy) 
management by an experienced cleft phoniatrician and/or speech therapist, and the plastic surgeon. SCS was recommended for children with severe VPI, however, the final decision was made together with the parents, taking into account the child's own wishes. Children developing post-surgical fistulas after the palatoplasty were identified. Symptomatic fistulas, with excessive nasal air emission or leakage of fluid and food, underwent surgical closure alone or in combination with SCS.

\section{Cleft characteristics and obstruction severity}

Cleft characteristics were distinguished and divided into groups according to extent of the cleft at the time of the primary palatoplasty. Also, width measurements $(\mathrm{mm})$ of the cleft were recorded if the information was available in the operative reports. We categorized cleft extent according to Jensen et al. (1988) (Figure 1) as follows: grade (1), cleft of only the soft palate; grade (2), cleft extending to $1 / 3$ of the hard palate or less; grade (3), cleft extending to over $1 / 3$ of the hard palate into the subtotal palate; grade (4), total cleft, cleft extending to the foramen incisivum. The border of the soft and hard palate served as the measure point for cleft width, divided into the following groups: $(1) \leq 9 \mathrm{~mm},(2)$ 10 to $12 \mathrm{~mm}$, and (3) $\geq 13 \mathrm{~mm}$. We categorized obstruction severity at infancy as follows: (1) prone positioning combined with bottle feeding, (2) feeding difficulties requiring nasogastric feeding, and (3) respiratory difficulties requiring non-invasive mechanical ventilation or invasive support such as nasopharyngeal tubes, endotracheal intubation, or tracheostomy.

\section{Surgical methods and surgeon}

Experienced cleft surgeons performed all surgeries. We divided age at primary surgery into (1) $\leq 9$ months, (2) 10 to 12 months, and (3) $\geq 13$ months. Through the years, the surgical techniques used in the primary palatoplasty have varied. The Veau-Wardill-Kilner $(\mathrm{V}-\mathrm{W}-\mathrm{K})$ technique has over time been replaced by the Bardach two-flap technique. This technique is more often used for wider clefts, while narrower and tensionless clefts are restored with a minimal incision technique described by Mendoza et al., (1994) or with the von Langenbeck technique. All techniques used in this study were performed with a one-stage closure. 
The techniques used for the SCS have also varied. Earlier, velopharyngeal flaps were the primary technique for this procedure, however, after 2005 Furlow re-palatoplasty became more commonly used at our clinic.

From each chart reviewed, we extracted the following variables: gender, date of birth, gestation age, cleft severity, other syndromes or anomalies, severity of respiratory obstruction and feeding difficulties, surgical technique used and date of primary palatoplasty, presence of post-surgical fistulas diagnosed visually by the surgeons, and, if performed, the date of fistula closure and, if performed, the date and technique of the SCS.

As children born early in the 1990s had shorter follow-ups due to the practices of the time, we analyzed the data at 8 years of age and at the time of data retrieval in February 2018. Our primary goal was to determine the incidence of SCS, fistula formation, and closure for symptomatic fistulas at 8 years of age and at data retrieval. Our secondary outcome was to examine and compare possible causal factors.

\section{Statistical analysis}

We collected data in Microsoft Excel and performed the analysis with Statistical Package for Social Sciences (SPSS), version 25. Categorical comparisons were performed with Pearson $\mathrm{X}^{2}$ test and Fisher exact test. Mann-Whitney U-test and Kruskal-Wallis test were used for comparison of nonparametric values and presented as median (IQR). Differences were considered significant when $\mathrm{P}<0.05$.

\section{RESULTS}

After exclusion (Figure 2), 78 patients with PRS (females, $n=48$ ) of the initial 103 patients remained 
(Table 1). The median gestation age was 39 weeks (range 30-42 weeks), while median age at primary palatoplasty was 10 months (range 6-16 months). The median follow-up was 14 years (range 8-27 years). The incidence for SCS in the total population was $43.6 \%(n=34)$ at 8 years and $47.4 \%(n=$ 37) at data retrieval. Additionally, two patients received palatal re-palatoplasty, one of whom had a palatal fistula. Furlow re-palatoplasty was the most used SCS technique $(n=23 / 34)$, but also pharyngeal flaps according to Honig's $(n=9 / 34)$ and Hogan's $(n=2 / 34)$ techniques were performed. Among the children receiving SCS, $13.9 \%(n=5)$ needed re-SCS before data retrieval. The median age at the first SCS was 6 years (Figure 3). Fistula formation occurred in $24.4 \%(\mathrm{n}=19)$, while closure for symptomatic fistulas at 8 years and at data collection was $7.7 \%(n=6)$ and $10.3 \%(n=8)$, respectively, in the total population.

\section{Gender}

We found no association between gender and SCS, fistula formation, or need for fistula closure.

\section{Cleft severity}

No patients in the study population had a cleft of only the soft palate. The majority of the clefts $(\mathrm{n}=$ 48) encompassed $>1 / 3$ of the hard palate extending into the subtotal cleft (Table 1). Cleft extent did not show a significant association with subsequent need for SCS, although the less severe clefts of $1 / 3$ of the hard palate or less had fewer corrective surgeries than the more severe clefts. An increasing rate of fistula formation and the corresponding need for fistula closure did show an association with cleft severity, although this was not a significant finding.

We found measurements of cleft width in the operative records of 58 patients. The median width was $10.5 \mathrm{~mm}$ (range 5-15 mm). Although wider clefts had a higher trend towards developing a palatal fistula, this finding was not statistically significant.

\section{Age at primary palatoplasty}

We observed wider clefts in children operated on at a later age $(\mathrm{P}=0.025)$, while no difference 
emerged concerning cleft extent (Table 3). However, the timing of primary palatoplasty did not have a significant impact on the need for secondary surgery or on fistula formation (Table 1).

\section{Primary palatoplasty}

Patients received similar surgical management at the primary closure of the palate in a one-stage procedure. The techniques most commonly employed were the Bardach two-flap technique $(\mathrm{n}=45)$ and the von Langenbeck technique $(\mathrm{n}=21)$ (Table 1). The surgical technique was not a significant factor in the need for SCS or in fistula formation.

\section{Surgeon}

Five experienced surgeons performed the primary palatoplasties, two of whom performed $76 \%(\mathrm{n}=$ 59) of the surgeries (Table 1). No significant association was present between surgeon and either need for SCS or fistula formation. However, a significant difference emerged between fistula closure and surgeon at data retrieval.

\section{Obstruction at infancy}

Degree of obstruction varied in the population. The majority of infants required nasogastric feeding or an airway intervention for respiratory distress of variable durations. Of these infants, $33 \%(\mathrm{n}=26)$ needed nasogastric feeding due to feeding difficulties, and $28 \%(\mathrm{n}=22)$ needed airway management in the form of noninvasive mechanical ventilation $(n=1)$, endotracheal intubation $(n=5)$, nasopharyngeal tubes $(n=11)$, or tracheostomy $(n=6)$. Two children received a gastrostomy with invasive airway intervention. No significant differences emerged between the obstruction categories and the need for SCS or fistula formation.

\section{Fistula location and need for re-operation and SCS}

Postoperative fistulas occurred most often at the border of the hard and soft palate (47.4\%) (Table 2). Before the age of 8 years, $38 \%(n=8)$ of the observed fistulas required closure, and by the time of data collection $48 \%(n=10)$. Patients with a fistula in the hard or soft palate more often needed SCS 
and fistula closure than patients with a fistula situated at the border of the hard and soft palate.

\section{DISCUSSION}

\section{Key findings}

This single-center observational study is one of a few studies assessing long-term speech outcome in a relatively large ns-PRS cohort. Our findings support the theory of high incidence for severe VPI in PRS, with a corresponding high incidence of SCS. We were surprised by the high fistula incidence and the need for surgical closure of symptomatic fistulas. However, we did not find any significant causal factors affecting the outcome of speech or fistulation, which might be explained by the size of the study population. Hence, major conclusions concerning implicating factors, such as anatomical variables, cannot be drawn, and further research with even larger cohorts is required. However, due to the rareness of the condition, studies with larger cohorts with precise study settings are challenging to conduct, and therefore, multicenter studies are needed.

Comparison with previous studies

Our study showed a rather high incidence of SCS, but it is nevertheless consistent with the widely ranging rates reported in PRS, $13.4 \%$ to $44.1 \%$ (Witt et al., 1997; de Buys Roessingh et al., 2008; Goudy et al., 2011; Patel et al., 2012; Stransky et al., 2013; Hardwicke et al., 2016; Morice et al., 2018). Although more precise study settings are necessary to be able to draw major conclusions and to compare the results with a similar study of the ICP population at the same cleft center (Gustafsson et al., 2018), we can see a trend towards a slightly higher overall incidence of SCS in the PRS population. Comparison of studies on PRS is often challenging because of differing study settings and diagnostic criteria of the sequence, concomitant syndromes, small cohorts, and short follow-up times. Only a limited number of studies are available concerning PRS and long-term speech outcome, and a few of these have similar findings. 
Differences in speech outcome between ICP and PRS have been described. After Hardwicke et al. (2016) matched PRS patients with ICP patients according to age, gender, and cleft extent (LAHSAL code), they still found a significant difference in speech outcome. This finding indicates the presence of contributing factors other than the extent of the cleft itself. Similarly, Stransky et al. (2013) found poorer speech characteristics in ns-PRS than in ICP, although no significant difference was noted in surgery rates. The etiology for PRS clefts is thought to occur from a triad of events during embryologic development; a retrognathic mandibula causes a retroposed and upward positioned tongue, which in turn interferes with palatal folding (Logjes et al., 2018). Beside the retrognathic and hypoplastic mandibula (Zellner et al., 2017), structures of the maxilla are described to diverge in PRS (Laitinen and Ranta, 1992; Laitinen, 1993; Bacher et al., 2000; Krimmel et al., 2009; Purnell et al., 2019). One can speculate whether the nasopharyngeal depth or the structures of the PRS soft palate diverge from those of the ICP soft palate. Some authors suggest that the fact that PRS is commonly associated with wider (Rintala et al., 1984; Godbout et al., 2014) and even longer (Godbout et al., 2014) clefts, compared with ICP, may be a predictive factor. As surgical closure of this cleft is challenging due to excessive tension, the palate is also susceptible to fistula formation and tissue scarring, resulting in an immobile palate with poor function. Yuan et al. (2016) postulated that closure of wider clefts may result in shorter palates that are more likely to develop VPI. Yet, no general consensus exists on PRS and its worse speech outcome compared with ICP. Likewise, the subsequent development of VPI in restored cleft palates is still unclear and believed to arise from multiple complex factors acting together. PRS abnormal facial and nasopharyngeal structures have an additional impact on the speech outcome.

In this study, we did not find any causal factors affecting the need for corrective surgeries or fistula occurrence in PRS. Our results are in line with the recent study of Morice et al. (2018), where no specific predictors for speech outcome were found among anatomic variables, such as cleft width 
and extent, glossoptosis, and retrognathia, or among respiration management at birth or muscle deficiency with EMG. Also, Filip et al. (2015) reported no significant association between cleft extent and VPI surgery rates in PRS. Although our finding was not significant, a trend for more severe clefts requiring corrective surgery was observed.

Speech characteristics may fluctuate during childhood as structures in the nasopharyngeal region mature; thus, most SCSs are performed at the end of early childhood (Andersson et al., 2010; Gustafsson et al., 2018). In examining speech and the subsequent need for SCS in individuals with restored orofacial clefts, accurate and long follow-ups are crucial. Studies observing speech outcome often have inadequate follow-up times, sometimes only early childhood. To obtain a comprehensive picture, we analyzed the dataset at 8 years, which served as the minimum age for inclusion in the study, but also at data retrieval. The median age at SCS was 6 years, which also reflects our aim of improving speech before school age (in Finland, the average age at the start of elementary school is 7 years). However, three patients underwent SCS and two patients received fistula closure after the age of 8 years.

Although pharyngeal flaps are an effective way of correcting VPI by narrowing the nasopharyngeal region with a posterior flap, respiratory obstruction and sleep apnea are commonly described complications (Abdel-Aziz et al., 2018). This is in contrast to Furlow re-palatoplasty, which seems to have a lesser tendency for postoperative respiratory obstruction. However, no general consensus has emerged as to whether one procedure improves VPI more efficiently than the other, and very few studies have been published on the topic (Dailey et al., 2006). Furlow re-palatoplasty was the primary SCS technique used at our clinic. Concerning surgical recovery and postoperative respiratory obstruction, we consider this technique to often be more suitable than pharyngeal flaps, particularly in small children.

Our fistula incidence (24\%) is consistent with reported rates of 0\% to 26\% (Witt et al., 1997; Goudy 
et al., 2011; Patel et al., 2012; Stransky et al., 2013; Filip et al., 2015; Morice et al., 2018) in PRS. The wide range in fistula incidence may be explained by differing cleft and maxillary characteristics. Parwaz et al. (2009) noted that the association between the width of the cleft and the palatal shelves is an important predictive factor for fistulation. No significant association emerged according to the surgeon or the surgical techniques used, although the techniques used for closure of more severe clefts more often resulted in fistulation. Fistula distribution in the palate was not a significant factor. Like other studies (Morice et al., 2018; Parwaz et al., 2009), we observed that fistula formation occurred most frequently $(n=9 / 19)$ at the border of the soft and hard palate. These fistulas rarely required surgical management in our study.

\section{Study strengths and limitations}

Strengths of the study include a large cohort of children with ns-PRS, all treated at a single center by a multidisciplinary cleft team. Moreover, all children received standardized longitudinal follow-up, the majority up to adolescence. A few limitations must also be noted, e.g. the retrospective study setting. In addition, not all children underwent genetic consultation during this time period, only unclear cases or children showing signs of syndromes. Nowadays, however, all children receive, or at least are offered, genetic consultation and appropriate investigation.

Comparing different surgical techniques performed by several surgeons is not ideal. However, the multiple surgeons and techniques used in this study reflect the long data collection period and the clinical praxis of that time. Although all surgeons are experienced and operate in a similar manner, we found that some closed wider clefts than others $(\mathrm{P}=0.001)$; no other variation was noted concerning cleft extent $(\mathrm{P}=0.073)$. Since closure of extensive PRS clefts is challenging, the primary palatoplasties are nowadays centralized exclusively to specific surgeons of the cleft team. In contrast to other studies on this topic, we did not examine the speech characteristics themselves. This would have been an interesting addition to our study. Nevertheless, such factors are difficult to compare with other studies since speech assessment varies widely among centers. In any case, our patients 
receiving SCS represented the group with substantial speech difficulties requiring corrective surgery. We did not assess the duration of airway management at infancy, and until 2005 polysomnography was not used as a standard examination to screen respiratory disturbances during sleep.

\section{CONCLUSION}

PRS with cleft palate is often associated with severe VPI and fistula formation after palatoplasty, almost invariably requiring SCS. An accurate and long-term follow-up is important for these individuals since speech problems are common. According to our findings, gender, age at primary palatoplasty, surgical technique, surgeon, cleft severity, and airway management at infancy are not associated with the need for secondary surgery. The development of VPI in ns-PRS is complex, most likely involving multiple factors. Larger study cohorts of PRS patients are required before any further conclusions can be drawn.

\section{REFERENCES}

ABDEL-AZIZ, M., HUSSIEN, A., KAMEL, A., AZOOZ, K. \& FAWAZ, M. 2018. The Impact of Velopharyngeal Surgery on the Polysomnographic Parameters After Cleft Palate Repair. $J$ Craniofac Surg, 29, 717-719.

ANDERSSON, E. M., SANDVIK, L., TORDAL, I. B. \& ABYHOLM, F. 2010. Pharyngoplasty after primary repair of clefts of the secondary palate. Scand J Plast Reconstr Surg Hand Surg, 44, 26-30.

BACHER, M., BACHER, U., GOZ, G., PHAM, T., CORNELIUS, C. P., SPEER, C. P., GOELZ, R., ARAND, J., WENDLING, F., BUCHNER, P. \& BACHER, A. 2000. Three-dimensional computer morphometry of the maxilla and face in infants with Pierre Robin sequence--a comparative study. Cleft Palate Craniofac J, 37, 292-302.

BASART, H., PAES, E. C., MAAS, S. M., VAN DEN BOOGAARD, M. J., VAN HAGEN, J. M., BREUGEM, C. C., COBBEN, J. M., DON GRIOT, J. P., LACHMEIJER, A. M., LICHTENBELT, K. D., VAN NUNEN, D. P., VAN DER HORST, C. M. \& HENNEKAM, R. C. 2015. Etiology and pathogenesis of robin sequence in a large Dutch cohort. Am J Med Genet A, 167A, 1983-92.

BECKER, D. B., GRAMES, L. M., PILGRAM, T., KANE, A. A. \& MARSH, J. L. 2004. The effect of timing of surgery for velopharyngeal dysfunction on speech. J Craniofac Surg, 15, 804-9.

BENJAMIN, B. \& WALKER, P. 1991. Management of airway obstruction in the Pierre Robin sequence. Int J Pediatr Otorhinolaryngol, 22, 29-37. 
BREUGEM, C. C., EVANS, K. N., POETS, C. F., SURI, S., PICARD, A., FILIP, C., PAES, E. C., MEHENDALE, F. V., SAAL, H. M., BASART, H., MURTHY, J., JOOSTEN, K. F., SPELEMAN, L., COLLARES, M. V., VAN DEN BOOGAARD, M. J., MURADIN, M., ANDERSSON, M. E., KOGO, M., FARLIE, P. G., DON GRIOT, P., MOSSEY, P. A., SLATOR, R., ABADIE, V. \& HONG, P. 2016. Best Practices for the Diagnosis and Evaluation of Infants With Robin Sequence: A Clinical Consensus Report. JAMA Pediatr, 170, 894-902.

BUSH, P. G. \& WILLIAMS, A. J. 1983. Incidence of the Robin Anomalad (Pierre Robin syndrome). Br J Plast Surg, 36, 434-7.

DAILEY, S. A., KARNELL, M. P., KARNELL, L. H. \& CANADY, J. W. 2006. Comparison of resonance outcomes after pharyngeal flap and furlow double-opposing z-plasty for surgical management of velopharyngeal incompetence. Cleft Palate Craniofac J, 43, 38-43.

DE BUYS ROESSINGH, A. S., HERZOG, G., CHERPILlOD, J., TRICHET-ZBINDEN, C. \& HOHLFELD, J. 2008. Speech prognosis and need of pharyngeal flap for non syndromic vs syndromic Pierre Robin Sequence. J Pediatr Surg, 43, 668-74.

FILIP, C., FERAGEN, K. B., LEMVIK, J. S., LINDBERG, N., ANDERSSON, E. M., RASHIDI, M., MATZEN, M. \& HOGEVOLD, H. E. 2015. Multidisciplinary Aspects of 104 Patients With Pierre Robin Sequence. Cleft Palate Craniofac J, 52, 732-42.

GLADE, R. S. \& DEAL, R. 2016. Diagnosis and Management of Velopharyngeal Dysfunction. Oral Maxillofac Surg Clin North Am, 28, 181-8.

GODBOUT, A., LECLERC, J. E., ARTEAU-GAUTHIER, I. \& LECLERC, L. D. 2014. Isolated versus pierre robin sequence cleft palates: are they different? Cleft Palate Craniofac J, 51, 406-11.

GOUDY, S., INGRAHAM, C. \& CANADY, J. 2011. The occurrence of velopharyngeal insufficiency in Pierre Robin Sequence patients. Int J Pediatr Otorhinolaryngol, 75, 1252-4.

GUSTAFSSON, C., HELIOVAARA, A., LEIKOLA, J. \& RAUTIO, J. 2018. Incidence of SpeechCorrecting Surgery in Children With Isolated Cleft Palate. Cleft Palate Craniofac J, 1055665618760889.

HARDWICKE, J. T., RICHARDS, H., CAFFERKY, L., UNDERWOOD, I., TER HORST, B. \& SLATOR, R. 2016. Outcomes of Cleft Palate Repair in Patients with Pierre Robin Sequence: A Matched Case-Control Study. Plast Reconstr Surg, 137, 927-35.

JENSEN, B. L., KREIBORG, S., DAHL, E. \& FOGH-ANDERSEN, P. 1988. Cleft lip and palate in Denmark, 1976-1981: epidemiology, variability, and early somatic development. Cleft Palate $J, 25,258-69$.

KRIMMEL, M., KLUBA, S., BREIDT, M., BACHER, M., DIETZ, K., BUELTHOFF, H. \& REINERT, S. 2009. Three-dimensional assessment of facial development in children with Pierre Robin sequence. J Craniofac Surg, 20, 2055-60.

LAITINEN, S. H. 1993. Sizes of dental arches in children with the Pierre Robin syndrome and isolated cleft palate aged from 0.2 to six years. Scand J Plast Reconstr Surg Hand Surg, 27, 285-90.

LAITINEN, S. H. \& RANTA, R. E. 1992. Cephalometric measurements in patients with Pierre Robin syndrome and isolated cleft palate. Scand J Plast Reconstr Surg Hand Surg, 26, 177-83.

LOGJES, R. J. H., BREUGEM, C. C., VAN HAAFTEN, G., PAES, E. C., SPERBER, G. H., VAN DEN BOOGAARD, M. H. \& FARLIE, P. G. 2018. The ontogeny of Robin sequence. Am J Med Genet A, 176, 1349-1368.

MENDOZA, M., MOLINA, F., AZZOLINI, C. \& YSUNZA RIVERA, A. 1994. Minimal incision palatopharyngoplasty. A preliminary report. Scand J Plast Reconstr Surg Hand Surg, 28, 199205. 
MORICE, A., RENAULT, F., SOUPRE, V., CHAPUIS, C., TRICHET ZBINDEN, C., KADLUB, N., GIUDICE, A., VAZQUEZ, M. P. \& PICARD, A. 2018. Predictors of speech outcomes in children with Pierre Robin sequence. J Craniomaxillofac Surg, 46, 479-484.

PARWAZ, M. A., SHARMA, R. K., PARASHAR, A., NANDA, V., BISWAS, G. \& MAKKAR, S. 2009. Width of cleft palate and postoperative palatal fistula--do they correlate? J Plast Reconstr Aesthet Surg, 62, 1559-63.

PATEL, K. B., SULLIVAN, S. R., MURTHY, A. S., MARRINAN, E. \& MULLIKEN, J. B. 2012. Speech outcome after palatal repair in nonsyndromic versus syndromic Robin sequence. Plast Reconstr Surg, 130, 577e-584e.

PRINTZLAU, A. \& ANDERSEN, M. 2004. Pierre Robin sequence in Denmark: a retrospective population-based epidemiological study. Cleft Palate Craniofac J, 41, 47-52.

PURNELL, C. A., JANES, L. E., KLOSOWIAK, J. L. \& GOSAIN, A. K. 2019. Mandibular CatchUp Growth in Pierre Robin Sequence: A Systematic Review. Cleft Palate Craniofac J, 56, 168-176.

RINTALA, A., RANTA, R. \& STEGARS, T. 1984. On the pathogenesis of cleft palate in the Pierre Robin syndrome. Scand J Plast Reconstr Surg, 18, 237-40.

STRANSKY, C., BASTA, M., SOLOT, C., COHEN, M., LOW, D. W., LAROSSA, D. \& JACKSON, O. 2013. Do patients with Pierre Robin sequence have worse outcomes after cleft palate surgery? Ann Plast Surg, 71, 292-6.

VATLACH, S., ARAND, J., ENGEL, C. \& POETS, C. F. 2014. Safety profile comparison between extemporaneous and a licensed preparation of caffeine citrate in preterm infants with apnea of prematurity. Neonatology, 105, 108-11.

WITT, P. D., MYCKATYN, T., MARSH, J. L., GRAMES, L. M. \& DOWTON, S. B. 1997. Need for velopharyngeal management following palatoplasty: an outcome analysis of syndromic and nonsyndromic patients with Robin sequence. Plast Reconstr Surg, 99, 1522-9; discussion 1530-4.

YUAN, N., DORAFSHAR, A. H., FOLlMAR, K. E., PENDLETON, C., FERGUSON, K. \& REDETT, R. J., 3RD 2016. Effects of Cleft Width and Veau Type on Incidence of Palatal Fistula and Velopharyngeal Insufficiency After Cleft Palate Repair. Ann Plast Surg, 76, 40610.

ZELLNER, E. G., REID, R. R. \& STEINBACHER, D. M. 2017. The Pierre Robin Mandible is Hypoplastic and Morphologically Abnormal. J Craniofac Surg, 28, 1946-1949. 
Tables and figures

TABLE 1. Incidence of speech-correcting surgeries (SCSs), fistulas, and operated fistulas.

TABLE 2. Location of palatal fistula and need for surgical closure and speech-correcting surgery (SCS).

TABLE 3. Cleft severity at the age of palatoplasty.

FIGURE 1. Modified categorization of cleft extent according to Jensen et al. (1988). Grade (1), cleft of only the soft palate; Grade (2), cleft extending to 1/3 of the hard palate or less; Grade (3), cleft extending to more than $1 / 3$ of the hard palate, reaching the subtotal cleft; Grade (4), total cleft, cleft extending to the foramen incisivum.

FIGURE 2. Population characteristics.

FIGURE 3. Kaplan-Meier graph of speech-correcting surgeries (SCSs) and fistula closure at specific ages. 
TABLE 1. Incidence of speech-correcting surgeries (SCS), fistulas, and operated fistulas.

\begin{tabular}{|c|c|c|c|c|c|c|c|c|c|c|c|c|c|}
\hline & \multirow[b]{2}{*}{$\mathrm{n}$} & \multicolumn{6}{|c|}{ SCS } & \multicolumn{2}{|c|}{ Fistula } & \multicolumn{4}{|c|}{ Operated fistula } \\
\hline & & 8 years & $P$ & Data retrieval $^{\mathrm{d}}$ & $P$ & age $(\mathrm{IQR})^{\mathrm{a}}$ & $P$ & & $P$ & 8years & $P$ & Data retrieval $^{\mathrm{d}}$ & $P$ \\
\hline Total & 78 & 34 (43.6) & & 37 (47.4) & & & & $19(24.4)$ & & $6(7.7)$ & & $8(10.3)$ & \\
\hline Gender & & & 0.971 & & 0.720 & & 0.240 & & 0.868 & & $1.000+$ & & $1.000+$ \\
\hline Male & 30 & $13(43.3)$ & & $15(50.0)$ & & $6.0(4.0-8.0)$ & & $7(23.3)$ & & $2(6.7)$ & & $3(10.0)$ & \\
\hline Female & 48 & $21(43.8)$ & & $22(45.8)$ & & $5.0(4.0-7.0)$ & & $12(25.0)$ & & $4(8.3)$ & & $5(10.4)$ & \\
\hline Cleft extent in HSCP & & & 0.341 & & 0.282 & & 0.809 & & $0.593+$ & & $0.848+$ & & $0.563+$ \\
\hline$\leq 1 / 3$ & 10 & $3(30.0)$ & & $3(30.0)$ & & $5.0(4.0-5.0)$ & & $1(10.0)$ & & $0(0.0)$ & & $0(0.0)$ & \\
\hline Total & 20 & $7(35.0)$ & & $8(40.0)$ & & $5.5(3.5-7.5)$ & & $6(30.0)$ & & $2(10.0)$ & & $3(15.0)$ & \\
\hline Cleft width ${ }^{\mathrm{b}}$ & & & 0.446 & & 0.802 & & 0.525 & & $0.248+$ & & $0.277+$ & & $0.277 \dagger$ \\
\hline$\leq 9 \mathrm{~mm}$ & 19 & $7(36.8)$ & & $8(42.1)$ & & $5.5(4.0-7.5)$ & & $3(15.8)$ & & $2(10.5)$ & & $2(10.5)$ & \\
\hline $10-12 \mathrm{~mm}$ & 27 & $14(51.9)$ & & $14(51.9)$ & & $6.0(4.0-7.3)$ & & $5(18.5)$ & & $1(3.7)$ & & $1(3.7)$ & \\
\hline$\geq 13 \mathrm{~mm}$ & 12 & $4(33.3)$ & & $7(50.0)$ & & $6.5(5.3-12.5)$ & & $5(41.7)$ & & $2(16.7)$ & & $2(16.7)$ & \\
\hline Age at palatoplasty ${ }^{c}$ & & & 0.437 & & 0.264 & & 0.452 & & $0.719+$ & & $0.634+$ & & $0.537 \dagger$ \\
\hline$\leq 9$ & 35 & $17(48.6)$ & & $19(54.3)$ & & $5.0(4.0-7.0)$ & & 7 (20.0) & & $4(11.4)$ & & $4(11.4)$ & \\
\hline $10-12$ & 29 & $13(44.8)$ & & $14(48.3)$ & & $6.0(4.8-7.30)$ & & $8(27.6)$ & & $2(6.9)$ & & $4(13.8)$ & \\
\hline Palatoplasty technique & & & $0.856+$ & & $0.916+$ & & 0.703 & & $0.586+$ & & $0.289+$ & & $0.110+$ \\
\hline Bardach & 45 & $20(44.4)$ & & $22(48.9)$ & & $5.5(4.0-7.0)$ & & $13(28.9)$ & & $6(13.3)$ & & $8(17.8)$ & \\
\hline Langebeck & 21 & $8(38.1)$ & & $9(42.9)$ & & $6.0(4.0-7.5)$ & & $4(19.0)$ & & $0(0.0)$ & & $0(0.0)$ & \\
\hline Mendoza & 9 & $4(44.4)$ & & $4(44.4)$ & & $6.0(4.3-7.8)$ & & $1(11.1)$ & & $0(0.0)$ & & $0(0.0)$ & \\
\hline V-W-K & 3 & $2(66.7)$ & & $2(66.7)$ & & $4.5(4.0-4.5)$ & & $1(33.3)$ & & $0(0.0)$ & & $0(0.0)$ & \\
\hline Surgeon & & & 0.463 & & 0.284 & & 0.690 & & $0.716+$ & & $0.087+$ & & $0.029+$ \\
\hline A & 31 & $11(35.5)$ & & $12(38.7)$ & & $6.0(4.3-7.0)$ & & $6(19.4)$ & & $0(0.0)$ & & $0(0.0)$ & \\
\hline B & 28 & $14(50.0)$ & & $15(60.7)$ & & $4.0(4.0-8.0)$ & & $9(32.1)$ & & $5(17.9)$ & & $6(21.4)$ & \\
\hline $\mathrm{C}$ & 10 & $6(60.0)$ & & $7(70.0)$ & & $5.0(4.0-7.0)$ & & $3(30.0)$ & & $1(10.0)$ & & $2(20.0)$ & \\
\hline $\mathrm{D}$ & 7 & $3(42.9)$ & & $3(42.9)$ & & $6.0(5.0-6.0)$ & & $1(14.3)$ & & $0(0.0)$ & & $0(0.0)$ & \\
\hline $\mathrm{E}$ & 2 & $0(0.0)$ & & $0(0.0)$ & & & & $0(0.0)$ & & $0(0.0)$ & & $0(0.0)$ & \\
\hline Obstruction & & & 0.308 & & 0.452 & & 0.200 & & 0.756 & & $0.231+$ & & $0.647 \dagger$ \\
\hline Positioning & 30 & $13(43.3)$ & & $15(50.0)$ & & $6.0(4.0-8.0)$ & & $8(26.7)$ & & $4(13.3)$ & & $4(13.3)$ & \\
\hline $\mathrm{NG}$ & 26 & $13(53.8)$ & & $14(53.8)$ & & $4.5(4.0-6.0)$ & & $5(19.2)$ & & $2(7.7)$ & & $3(11.5)$ & \\
\hline $\mathrm{AI}$ & 22 & $8(36.4)$ & & $8(36.4)$ & & $6.5(4.5-7.8)$ & & $6(27.3)$ & & $0(0.0)$ & & $1(4.5)$ & \\
\hline
\end{tabular}

Categorical data are presented as n (\%). Continuous variables are presented as median (IQR, interquartile range). + Fisher's exact test.

Abbreviations: HSCP = Hard and soft cleft palate, V-W-K = Veau-Wardill-Kilner, NG = Nasogastric tube, AI = Airway intervention

${ }^{\mathrm{a}}$ Age (years) at first SCS, ${ }^{\mathrm{b}}$ Data of 58 patients, ${ }^{\mathrm{c}}$ Months, ${ }^{\mathrm{d}}$ Includes all patients (at 8 years and after 8years). 

TABLE 2. Location of palatal fistula and need for surgical closure and speech-correcting surgery (SCS).

\begin{tabular}{|c|c|c|c|c|c|c|c|c|c|}
\hline & \multirow{2}{*}{$\begin{array}{c}\text { Fistula } \\
\text { n (\%) }\end{array}$} & \multicolumn{4}{|c|}{ Operated fistula } & \multicolumn{4}{|c|}{ SCS } \\
\hline & & 8 years & $P$ & Data retrieval $^{\mathrm{a}}$ & $P$ & 8 years & $P$ & Data retrieval $^{\mathrm{a}}$ & $P$ \\
\hline Total & 19 & $6(31.6)$ & & $8(42.1)$ & & $6(31.6)$ & & $7(36.8)$ & \\
\hline SP & $4(21.1)$ & $4(66.7)$ & $0.107+$ & $4(66.7)$ & $0.056+$ & $4(66.7)$ & $0.107 \dagger$ & $4(66.7)$ & $0.097 \dagger$ \\
\hline Border of SP and HP & $9(47.4)$ & $1(11.1)$ & & $1(11.1)$ & & $1(11.1)$ & & $1(11.1)$ & \\
\hline HP & $6(31.6)$ & $1(25.0)$ & & $3(75.0)$ & & $1(25.0)$ & & $2(50.0)$ & \\
\hline
\end{tabular}

†Fisher's exact test

Abbreviations: $\mathrm{SP}=$ Soft palate, $\mathrm{HP}=$ Hard palate .

${ }^{a}$ Includes all patients (at 8 years and after 8 years). 
TABLE 3. Cleft severity at the age of palatoplasty.

\begin{tabular}{|c|c|c|c|c|c|c|c|c|c|c|}
\hline & n $(\%)$ & & Cleft width & & & n (\%) & & Cleft extent & & \\
\hline $\begin{array}{l}\text { Age at } \\
\text { palatoplasty }{ }^{a}\end{array}$ & 58 & $\leq 9 \mathrm{~mm}$ & $10-12 \mathrm{~mm}$ & $\geq 13 \mathrm{~mm}$ & $P$ & 78 & $\leq 1 / 3$ & $\begin{array}{c}>1 / 3- \\
\text { subtotal }\end{array}$ & Total & $P$ \\
\hline$\leq 9$ & 28 & $11(39.3)$ & $16(57.1)$ & $1(3.6)$ & \multirow[t]{3}{*}{$0.025+$} & 35 & $3(8.6)$ & 24 (68.6) & $8(22.9)$ & \multirow[t]{3}{*}{$0.188+$} \\
\hline $10-12$ & 21 & $6(28.6)$ & $8(38.1)$ & 7 (33.3) & & 29 & $7(24.1)$ & $15(51.7)$ & $7(24.1)$ & \\
\hline$\geq 13$ & 9 & $2(22.2)$ & $3(33.3)$ & $4(44.4)$ & & 14 & $0(0.0)$ & $9(64.3)$ & $5(35.7)$ & \\
\hline
\end{tabular}

Fisher's exact test

${ }^{\mathrm{a}}$ Months, ${ }^{\mathrm{b}}$ Data of 58 patients 
Grade 1

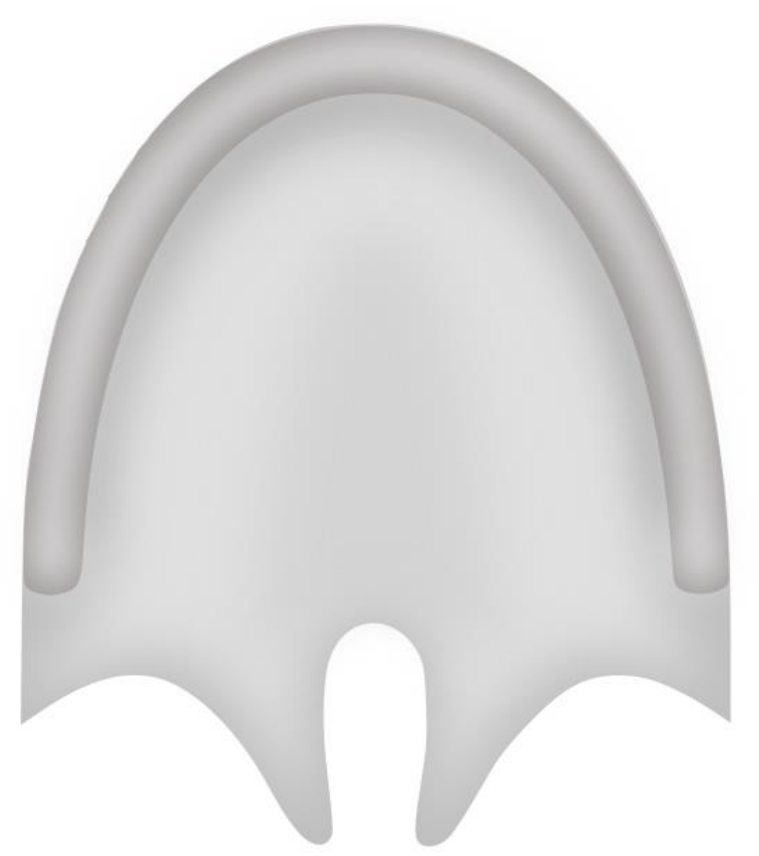

Grade 3.

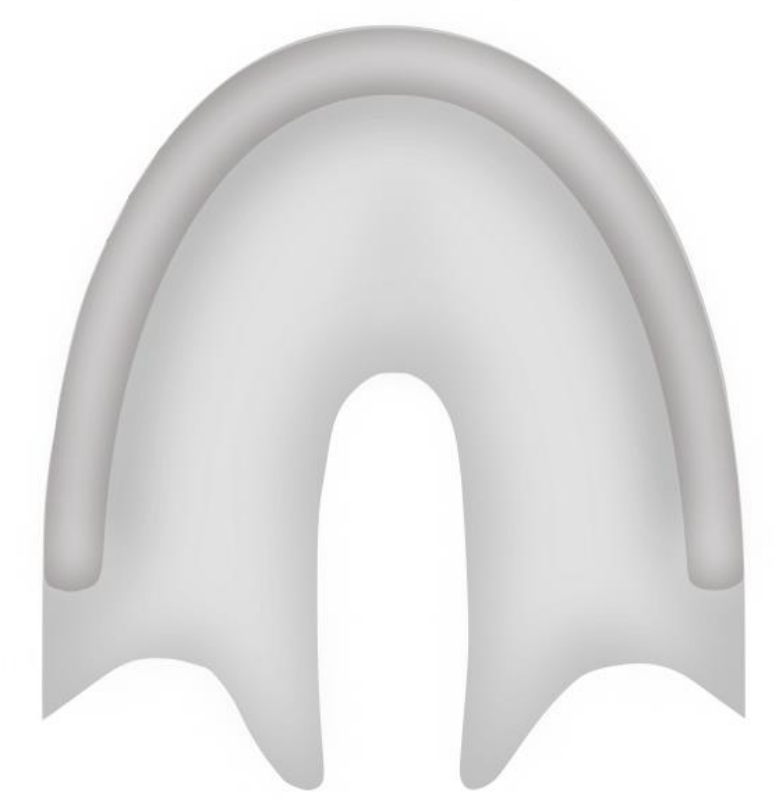

Grade 2.

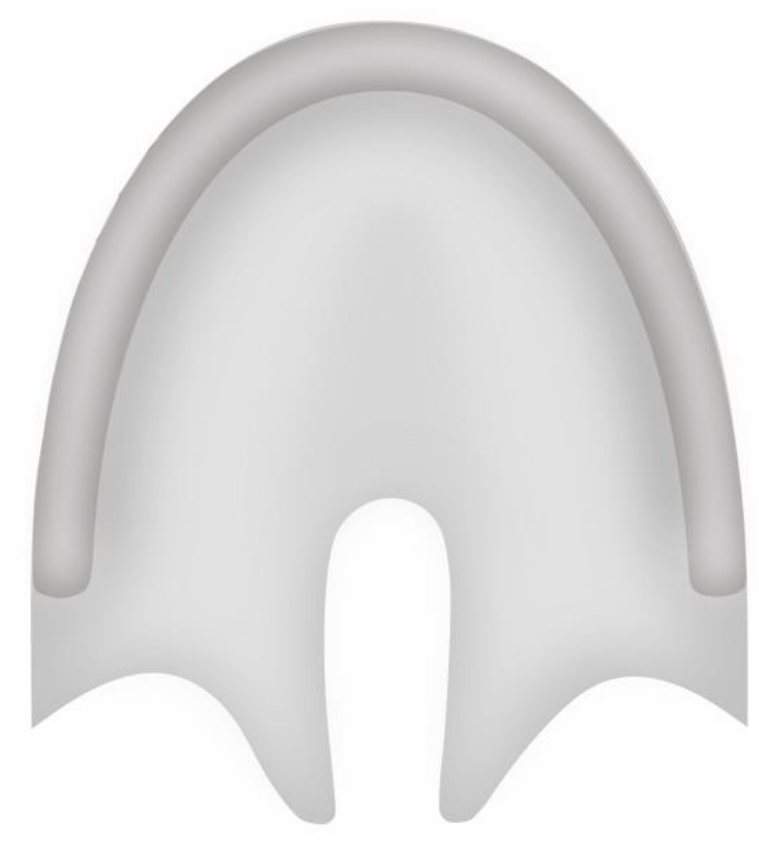

Grade 4.

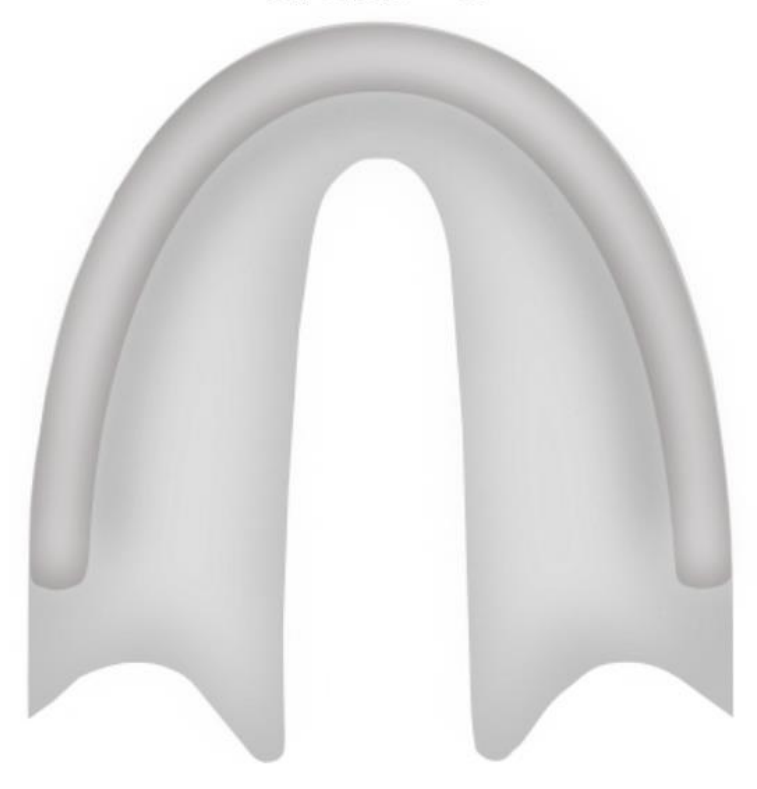

Figure 1 
103 Pierre Robin Sequence patients born 1990-2009

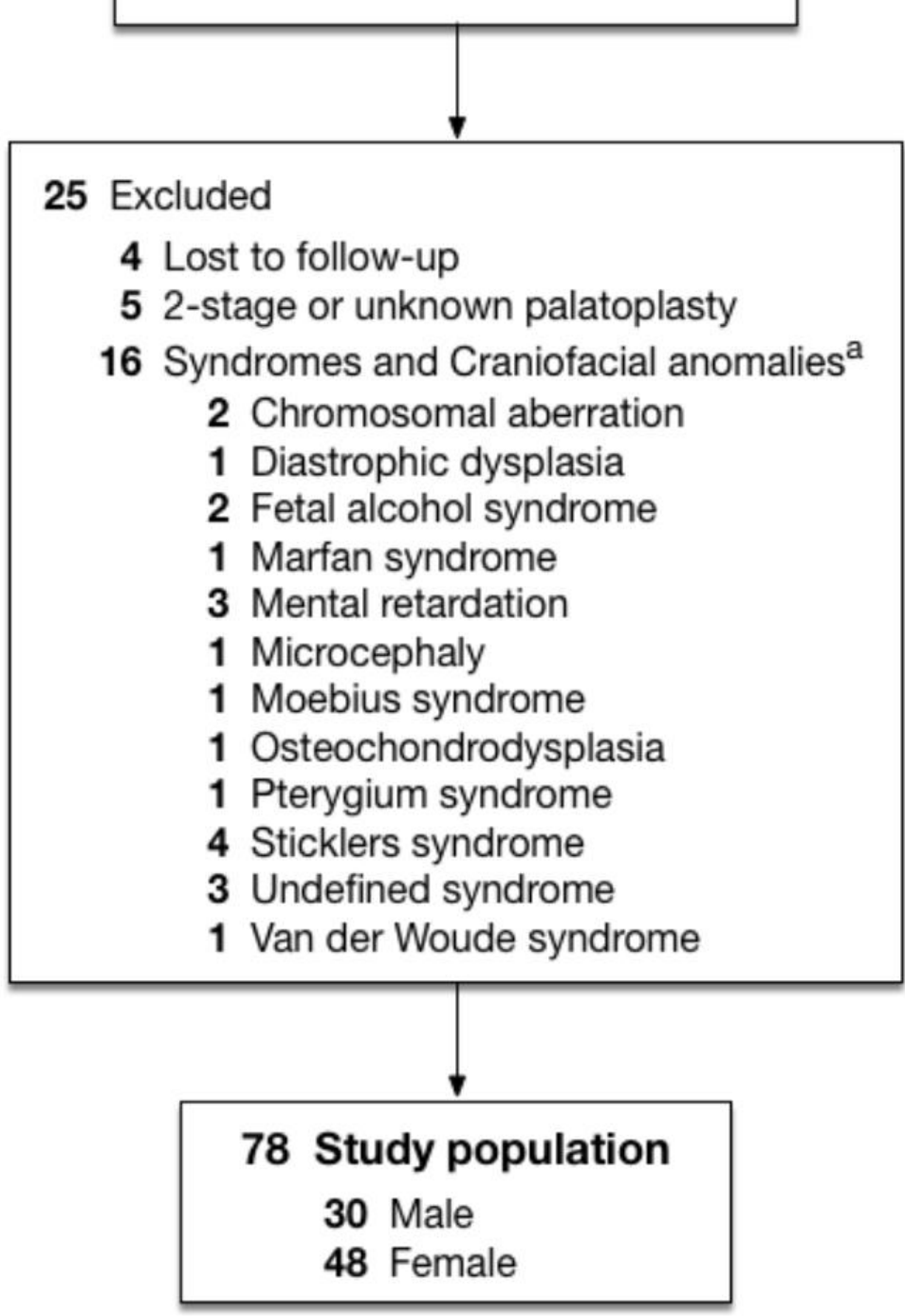

a Some children had multiple syndromes and/or craniofacial anomalies.

Figure 2 


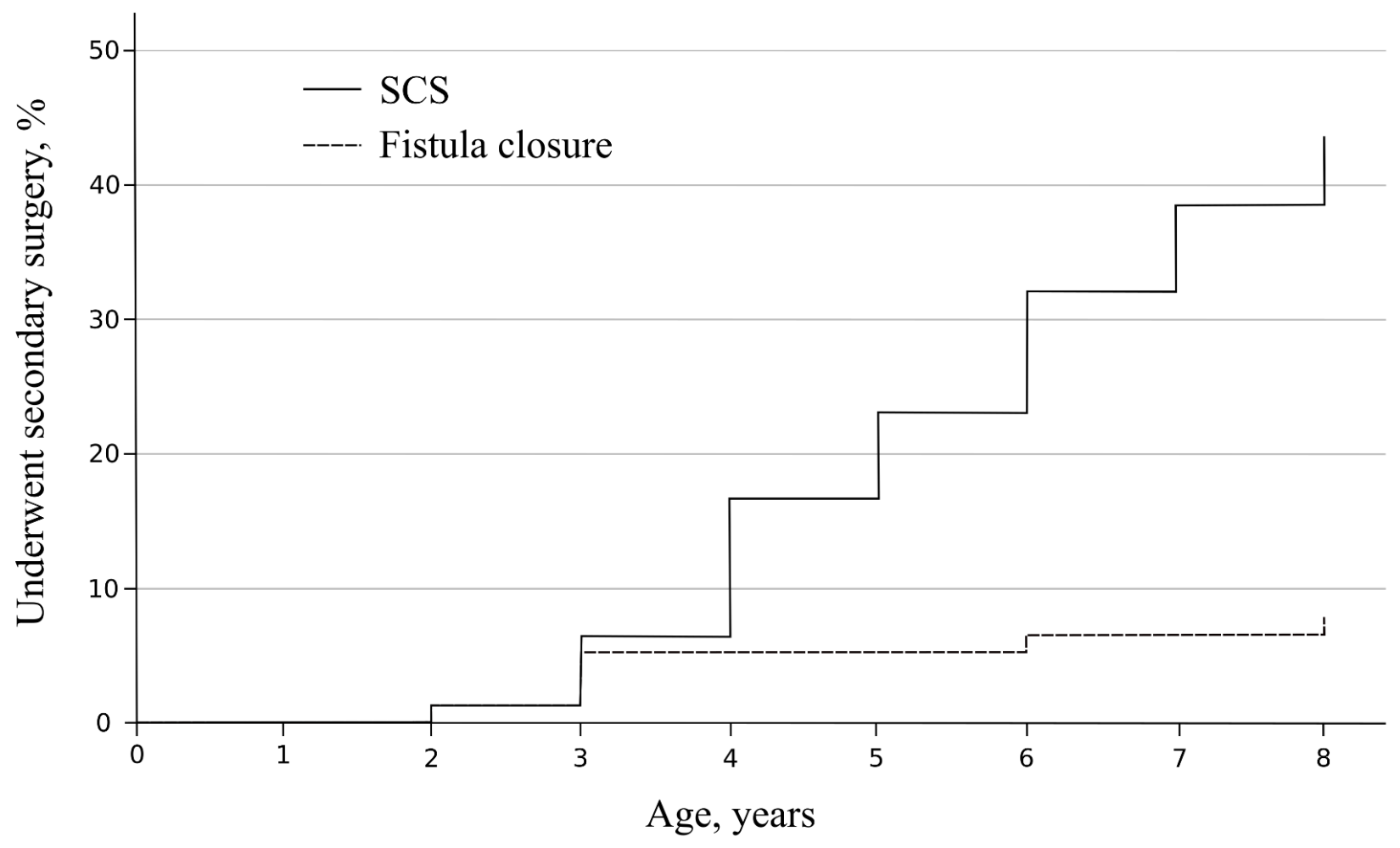

K-M Curve 